Research Article

\title{
Experimental Study of the Characteristic Changes of Coal Resistivity during the Gas Adsorption/Desorption Process
}

\author{
Zengchao Feng $\mathbb{D},{ }^{1}$ Chen Wang $\left(\mathbb{D},{ }^{1}\right.$ Dong Dong, ${ }^{2}$ Dong Zhao $\mathbb{i},{ }^{3}$ and Dong Zhou ${ }^{3}$ \\ ${ }^{1}$ Key Laboratory of Insitu Property Improving Mining of Ministry of Education, Taiyuan University of Technology, No. 18 \\ Xinkuangyuan Road, Wanbailin District, Taiyuan, Shanxi 030024, China \\ ${ }^{2}$ Xishan Coal and Electricity Group Co. Ltd, No. 319 Xikuang Street, Wanbailin District, Taiyuan, Shanxi 030024, China \\ ${ }^{3}$ College of Mining Engineering, Taiyuan University of Technology, No. 18 Xinkuangyuan Road, Wanbailin District, Taiyuan, \\ Shanxi 030024, China
}

Correspondence should be addressed to Zengchao Feng; zc-feng@163.com and Chen Wang; wangchen_tyut@163.com

Received 24 April 2018; Accepted 14 June 2018; Published 21 October 2018

Academic Editor: Antonio Riveiro

Copyright $(92018$ Zengchao Feng et al. This is an open access article distributed under the Creative Commons Attribution License, which permits unrestricted use, distribution, and reproduction in any medium, provided the original work is properly cited.

To study the influence of gas adsorption-desorption on the resistivity of coal, the resistivity changes in conditions of continuous adsorption/desorption and isovolumetric adsorption/desorption were tested by high-precision resistance measurement, and the relationship between coal resistivity and gas content was investigated. The results show that gas adsorption/desorption has obvious effects on the resistivity of coal. Similar behavior was observed both in continuous adsorption/desorption and in isovolumetric adsorption/desorption experiments. The coal resistivity decreased gradually at the very beginning and then tended to stabilize as the gas adsorption capacity increased; in the process of gas desorption, the resistivity demonstrated a linear relationship with gas content. When comparing resistivities for the different adsorption modes, it was found that, for the same gas content in each mode, the resistivity change in the isovolumetric adsorption experiment was more obvious than in the continuous adsorption experiment. Also, the coal resistivity in the isovolumetric experiment differed further from the original figure when the desorption ended. The results are significant for predicting gas content in the coal mining process.

\section{Introduction}

Coalbed methane (CBM) is an unconventional natural gas that is associated with coal and is predominantly adsorbed in the coal seam. China has abundant CBM resources. It has been estimated that 36.81 trillion cubic meters of CBM resources are present in coal at depths of 2000 meters or less, ranking third in the world. CBM development not only optimizes energy structure and meets the increasing clean energy needs, but it is also an effective way to control air pollution. There is also an urgent need for safe production in the coal industry in China.

Coal seam gas content is pivotal in the prevention of gasrelated disasters and gas utilization in underground coal mines. The accurate determination of coal gas content is the foundation of gas control and utilization [1-3]. Therefore, accurate coal gas content measurement in coal seams is of great significance to the exploitation and utilization of CBM. At present, the main methods of predicting gas content use both direct and indirect measurement techniques. Direct measurement (gas desorption measurement) is quick and provides timely information; however, quantity estimates measured in this way often underestimate true values, since the method cannot relate the exact loss of gas from a coal seam to that from a sealed vessel. Indirect measurement is more complicated. First, the gas pressure is measured in an underground coal mine. Then, a gas adsorption coefficient is determined in the laboratory, and the gas content is calculated. In addition, many different methods have been proposed. The amplitude variation with offset (AVO) seismic technique has been proposed for predicting gas content in coal seams [4]. Mathematical geological technology and methods allow prediction of gas content to be standardized and quantified [5]. The generalized regression neural 
network (GRNN) approach has been used to predict gas content in an unexploited coal seam [6].

Resistivity is an electrical property of ore and rock. Coal is a heterogeneous medium, and its adsorption/desorption of gas affects its resistivity. At present, studies in China and elsewhere have mainly focused on electrical resistivity and dielectric constant of coal and rock. Dindi et al. [7] measured the thermal and electrical conductivity of coal. Mahmood et al. [8] simulated reservoir conditions in the laboratory for measuring rock resistivity. Marland et al. [9] measured and researched the dielectric constant of coal at microwave frequency. The results showed that the dielectric properties of coal decrease with the degree of deterioration of coal, and the moisture and mineral components of coal increase the dielectric properties of coal. $\mathrm{Xu}$ et al. [10] investigated the influence of frequency on the conductivity of outburst coal and found that, at the microwave frequency, the AC conductivity of the coal in the outburst region increases with the increase of the frequency, and the conductivity has fractal characteristics. Xu [11] measured the electrical parameters of eight samples of coal of different ranks. Wang et al. [12] studied the variation of electrical parameters in the process of uniaxial compression of coal containing no gas. Yang [13] investigated the possibility of predicting coal and gas outbursts by testing the change of coal resistivity.

However, the aforementioned studies were mainly to test the electrical parameters of coal under different conditions. Due to the limitations of the research methods, the relationship between change of coal resistivity and gas content at the adsorption-desorption level has not previously been investigated. The present study carried out experiments to test the change of coal resistivity during adsorption and desorption of gas, with the aim of specifying a new method of predicting coal gas content.

\section{Experimental Sample and Apparatus}

The coal tested was anthracite produced by Shijiazhuang Coal Mine, Yangquan Coal Industry Group, China. A cylindrical sample (diameter $100 \mathrm{~mm}$; length $155 \mathrm{~mm}$ ) was prepared using a drilling machine and then treated as follows: (i) The sample was dried in an electrothermostatic oven. (ii) Two electrodes (diameter $15 \mathrm{~mm}$ ) with wire leads were sealed at both ends of the test specimen. (iii) The sample was put in an adsorption container. Proximate analysis of the coal is given in Table 1 .

The experimental apparatus in Figure 1, developed independently by the Institute of Mining Technology, Taiyuan University of Technology, mainly included (1) electrothermostatic water bath; (2) apparatus of injecting gas; (3) retrofitted adsorption device; (4) precise digital manometer (2.5 MPa); (5) apparatus for collecting desorbed gases; (6) TH2515 DC resistance meter; (7) gas collection system; and (8) vacuum pump.

\section{Experimental Process}

The experiment was designed to test the electrical resistance of coal sample during the adsorption/desorption process to
Table 1: Proximate analysis of tested coals.

\begin{tabular}{lc}
\hline Parameters & \\
\hline Analytic moisture content (\%) & 1.359 \\
Ash yield (\%) & 13.13 \\
Volatile matter (\%) & 7.1115 \\
\hline
\end{tabular}

determine the relationship between the electrical resistivity of the coal sample and gas content of the sample. The experimental method is given in Table 2. The coal sample continuously adsorbed gas until equilibration in Experiments 1,2 , and 3 . The valve between the methane cylinder and the adsorption device was opened, and adsorption proceeded from the initial pressure to equilibrium. The equilibrium pressure was then recorded. Then, the gas was desorbed. The change in electrical resistivity was tested during both processes.

Experiment 4 measured isovolumetric adsorption. Firstly, the initial pressure in methane cylinder was maintained at $1 \mathrm{MPa}$ while equal volumes of gas were injected into the adsorption device in stages. When the resistivity of the coal sample no longer changed, the equilibrium pressure was recorded. This gas injection procedure was repeated three times. By the end of the third injection stage, it was observed that the resistivity of the coal sample no longer changed with additional gas content, so the gas injection was stopped. An equal volume of desorption was then performed, each time desorbing one liter of gas. The static resistance was determined after each rebalance in both processes.

The experimental procedure was as follows:

(1) The sample was placed in the electrothermostatic loft dryer. The resistance of the dry coal sample was determined at different constant temperatures.

(2) The sample was placed into the apparatus, which was completely gas tight and connected to the resistance meter.

(3) A vacuum pump was used to remove the remaining gas in the experimental apparatus, and then methane was injected (at specific pressure) into the retrofitted adsorption device until an equilibrium adsorption pressure was reached.

(4) A gas collection system, using displacement of water and a rotor flow meter, was used to precisely determine the volume of desorbed methane (precision $\pm 2 \mathrm{~mL}$ ), while simultaneously recording changes in the collected gas volume and in the resistivity of the coal sample.

(5) The test method for measuring isovolumetric adsorption was described in detail above. During gas adsorption, the resistance of the coal sample was recorded after each adsorption equilibrium pressure was reached.

(6) An isovolumetric gas was released during desorption, and the resistance of the coal sample was measured after each adsorption rebalancing. 


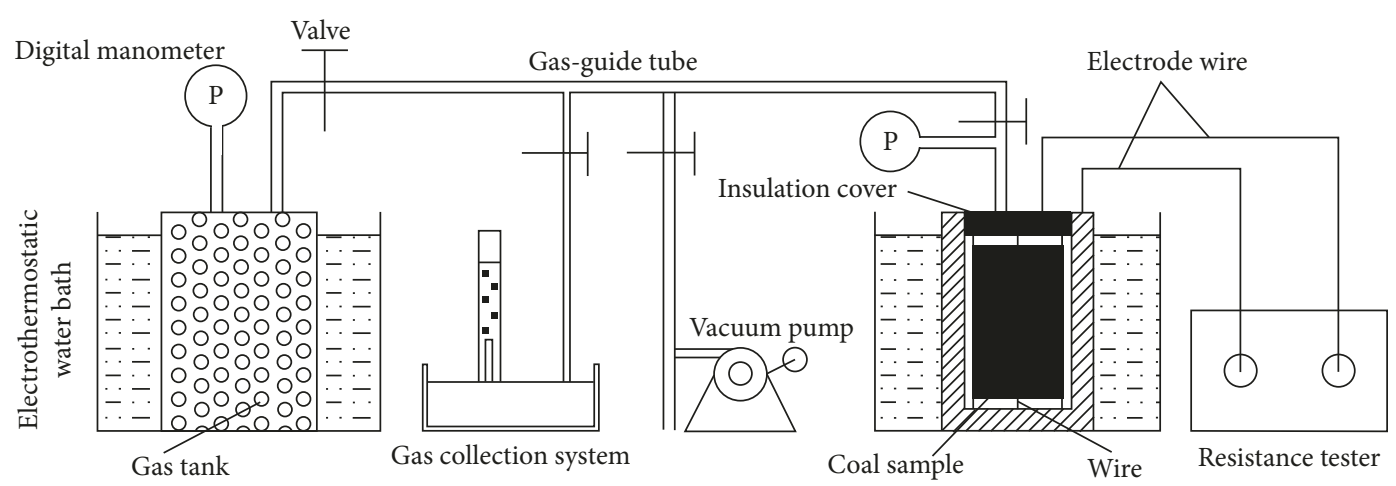

FIgURE 1: Test system for measuring the resistivity of coal sample.

TABLE 2: Experimental program.

\begin{tabular}{lccc}
\hline No. & Experimental method & Initial pressure of methane cylinder (MPa) & Equilibrium pressure (MPa) \\
\hline 1 & Continuous adsorption/desorption & 0.5 & 0.323 \\
2 & Continuous adsorption/desorption & 0.75 & 0.442 \\
3 & Continuous adsorption/desorption & 1.0 & 0.534 \\
4 & Isovolumetric adsorption/desorption & 1.0 & 0.72 \\
\hline
\end{tabular}

In these experiments, the data were collected continuously, and the time interval was adjusted to suit the speed of adsorption. The storage function of the resistor was opened in advance to ensure that the change of coal resistance is correctly recorded.

3.1. Method of Calculating Gas Content. Firstly, the change of gas pressure with resistivity change was recorded. To compare it with subsequent desorption curves, the gas pressure was converted to volume at standard temperature and pressure (STP) and then divided by the mass to obtain the gas content.

Using modified Boyle's law, the conversion was performed under isothermal conditions:

$$
\lambda P_{1} V_{1}=P_{2} V_{2} \text {, }
$$

where $\lambda$ is the coefficient of gas compressibility, $P_{1}$ is the gas pressure, $V_{1}$ is the volume of the adsorption apparatus, $P_{2}$ is the pressure at STP, and $V_{2}$ is the volume of gas at STP.

The free gas volume in the adsorption apparatus was calculated from Equation (1). The gas content is given by

$$
q=\frac{V_{2}-V_{2}^{\prime}}{m}
$$

where $q$ is the gas content, $m$ is the quality of dry coal sample, and $V_{2}^{\prime}$ is the free gas volume at STP.

\section{Experimental Results and Analyses}

\subsection{Variation of Resistivity with Gas Content during Continuous Adsorption/Desorption}

4.1.1. Change of Coal Resistivity with Change of Temperature. Figure 2 shows the coal resistivity at different temperatures. Between $30^{\circ} \mathrm{C}$ and $90^{\circ} \mathrm{C}$, the resistivity of the coal was clearly affected by temperature, and the coal resistivity trend was

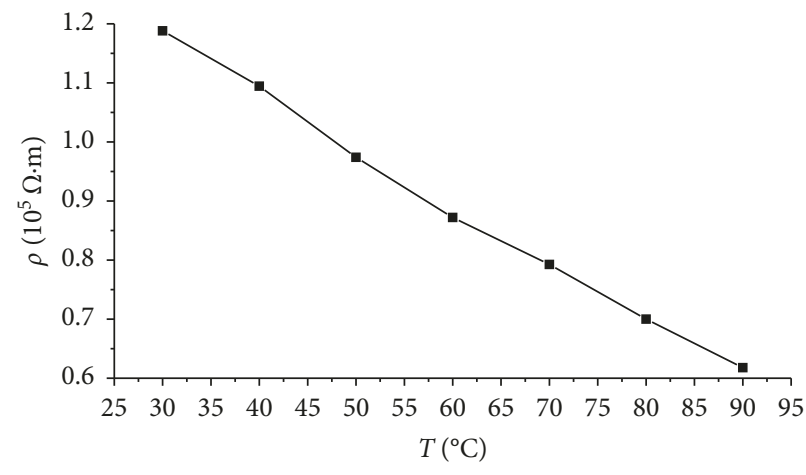

FIgURE 2: Resistivity of coal vs. temperature.

linear. The relationship between resistivity and temperature is given by

$$
\rho_{T}=\rho_{0}(1+\alpha T)
$$

where $\rho_{T}$ is the resistivity at temperature $T, \rho_{0}$ is the resistivity at $T=0^{\circ} \mathrm{C}$ in linear conditions, and $\alpha$ is the temperature coefficient.

At the molecular level, the resistivity of the coal sample decreases as temperature rises because anthracite is a poor semiconductor. The kinetic energy of electrons in the lowenergy valence band of semiconductors increases with the rise of temperature, and they are stimulated to move to a higher energy level; conductivity then increases and resistivity decreases.

4.1.2. Variation of Resistivity with Gas Content during Continuous Adsorption Process. Figure 3 shows that greater equilibrium pressure results in more obvious variation of resistivity. As adsorption proceeds at a decreasing rate $[14,15,16]$, the rate of resistivity decrease also slows. As the 


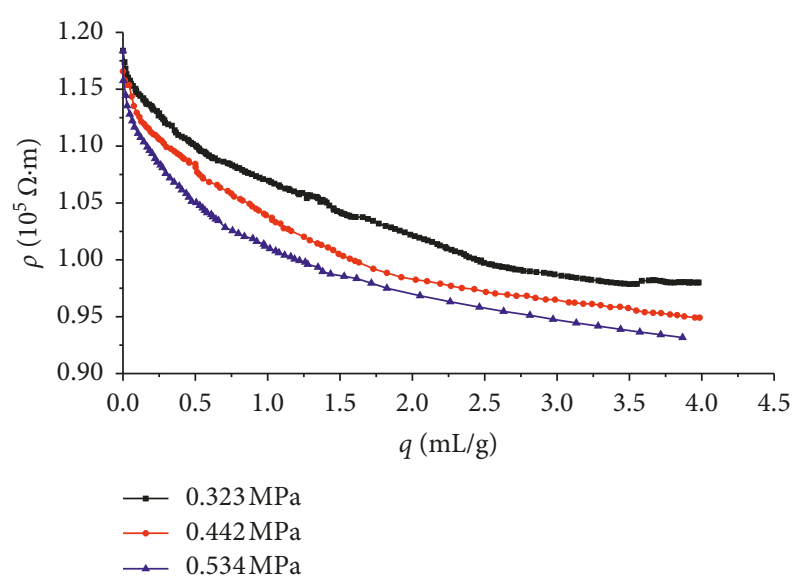

FIgURE 3: Resistivity of coal vs. change of gas content during continuous adsorption.

process approaches equilibrium, new pore fissures are produced in the coal, causing a slight rebound in the resistivity. In the later stage of adsorption, however, the skeletal structure of the coal has barely deformed, so its resistivity does not change with increased gas content. The resistivity curves at the three equilibrium pressures were analyzed for the case where the gas content remained identical.

Gas adsorption is a continuous heat-release process $[17,18]$ that causes the temperature of the coal to rise. The resistivity of anthracite, since it is a poor semiconductor, decreases with rising temperature (Figure 2). Gas adsorption causes swelling deformation, which is enhanced by the heat released by gas adsorption. As a result, the porosity of the coal decreases, and the pore surface energy decreases and the binding force of electrons with ions on the surface of the coal weaken. At the same time, the rising gas pressure in the pores compresses the coal skeleton and lowers resistivity [19]. Therefore, in the process of gas adsorption, the coal resistance rate is affected both by adsorption heat and expansion deformation.

4.1.3. Variation of Resistivity with Gas Content during Continuous Desorption. Figure 4 shows that the resistivity curves at different equilibrium pressures have the same slope. The greater the adsorption equilibrium pressure, the more obviously the resistivity varies during desorption, and the further the resistivity deviates from its original value when desorption is complete. During gas desorption, the relationship between the resistivity and gas content of the coal sample is linear.

The coal resistivity is mainly affected by the absorption of heat and contraction deformation. Gas desorption, which is endothermic, lowers the coal temperature and reduces the free energy at the surface of the coal. The surface electrons jump from the conduction band to the forbidden band, reducing the conductivity and increasing the resistivity (as shown in Figure 2). Contraction deformation increases the porosity [20], which leads to increased resistivity. Since the entire experimental apparatus was maintained at constant

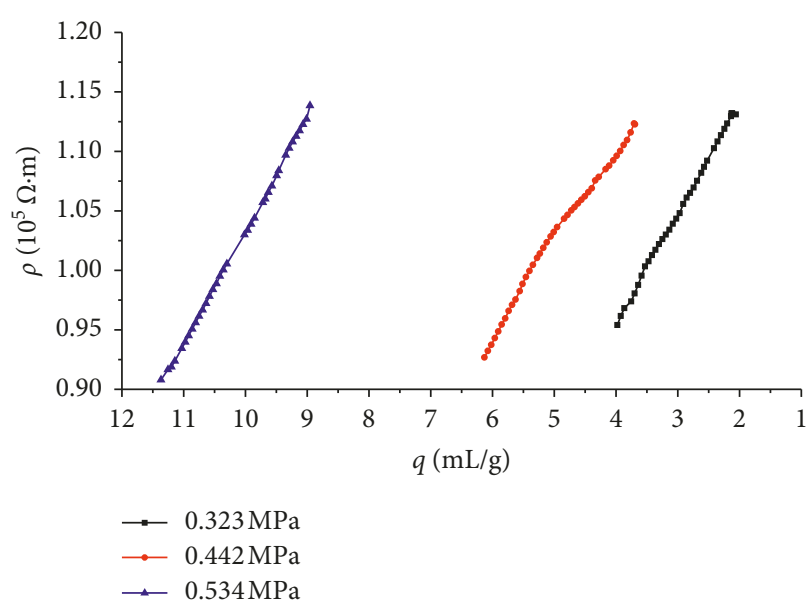

FIGURE 4: Resistivity vs. gas content during continuous desorption.

temperature, external heat rapidly replenishes the heat lost from the coal during gas desorption, which buffers the contraction deformation; this results in the observed linear relationship between resistivity and residual gas content in the coal sample.

The resistivity of the coal sample does not return to the preadsorption state after gas desorption; that is, the variation in resistivity is less when desorption is completed than when adsorption is completed (Figure 4). The coal sample retains some residual deformation: the greater the equilibrium pressure, the larger the residual deformation. This is because when the gas is released by desorption, micropores and microcracks forced open by the gas pressure close when the gas pressure suddenly drops, trapping some gas in the coal $[21,22,23,24]$, causing the residual deformation of the coal mentioned above, so its resistivity is not being restored its original value.

\subsection{Variation of Resistivity with Gas Content during Isovolumetric Adsorption/Desorption}

4.2.1. Variation of Resistivity for Isovolumetric Adsorption. Data were recorded continuously during the continuous adsorption experiment, whereas in the isovolumetric adsorption experiment the resistance of the coal sample was recorded only after each adsorption was rebalanced, ignoring any variation. The different approach was due to the fact that the former is a dynamic process and the latter is a static process; thus, the curves assume a different form. The resistivity of the coal decreased in the early stage of adsorption and then rebounded and fell rapidly. Finally, it hardly changed (Figure 5). The whole process shows the same pattern as in the continuous adsorption experiment.

4.2.2. Variation of Resistivity for Isovolumetric Desorption. The curve of isovolumetric desorption is presented in Figure 6. It was found that the variable trend is consistent with that of continuous desorption. This is due to the fact that, as discussed, gas desorption is an endothermic process, resulting in a fall in coal temperature. Microscopically, the 


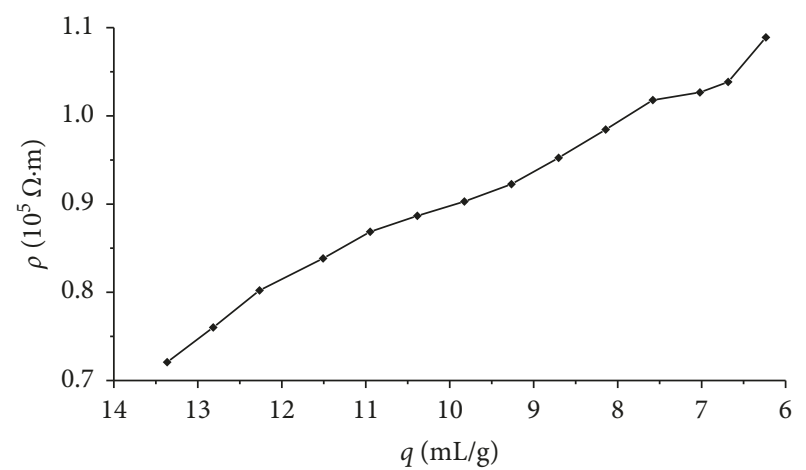

FIgURe 5: Resistivity vs. gas content during isovolumetric adsorption.

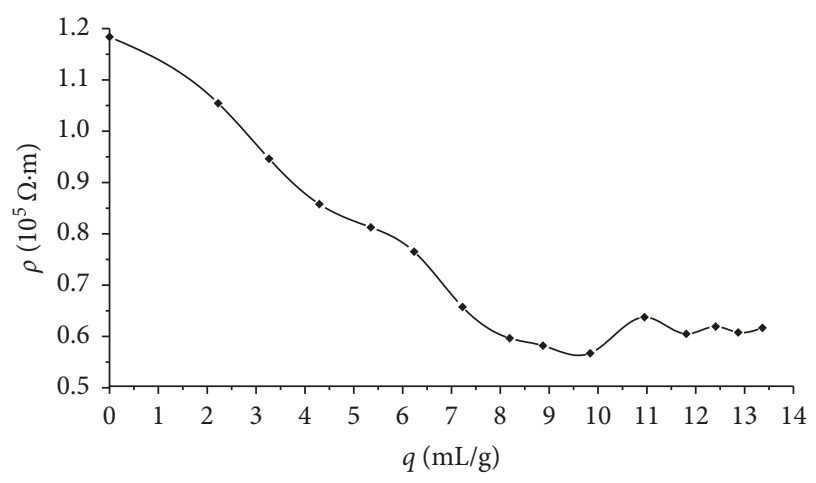

Figure 6: Resistivity vs. gas content during isovolumetric desorption.

surface electrons jump from the conduction band to the forbidden band, reducing the conductivity. Macroscopically, temperature decrease promotes contraction deformation of the coal, resulting in greater pore volume and therefore greater resistivity. At the same time, release of gas by desorption also allows the coal to contract as the compressive pressure on the coal particles gradually decreases. The combination of these two factors is evidenced by a linear increase of coal resistivity as gas desorption proceeds.

\section{Discussion}

5.1. Influence of Different Adsorption Methods on the Resistivity of Coal. The graphs of coal resistivity change during continuous adsorption and during isovolumetric adsorption show that the different gas injection modes led to different variations in the coal resistivity, but with the same change trends. The adsorbed amount in the former was less than in the latter, as were the ranges of resistivity variation. This indicates that the variation of coal resistivity differs for the two adsorption modes.

The resistivities at an adsorption equilibrium pressure of $0.534 \mathrm{MPa}$ for continuous adsorption and for isovolumetric adsorption are compared in Figure 7, which shows the resistivity changes for the two adsorption methods for the same gas content, for eight isovolumetric gas injection stages.

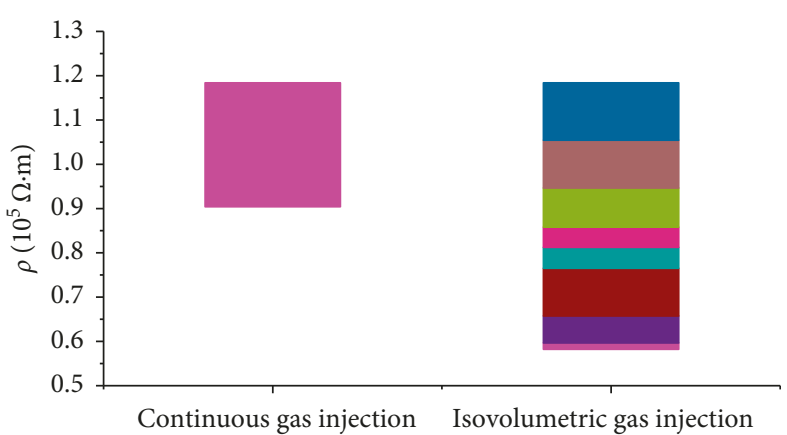

FIgURE 7: Corresponding resistivity change for two modes of adsorbing the same gas content.

It can be seen that when the coal sample adsorbed the same gas content, the change of resistivity was more obvious during isovolumetric gas adsorption. The reason is that the gas pressure on the coal sample was more uniform in isovolumetric gas adsorption, and the internal structure of the coal changed greatly, which led to the obvious changes in resistivity.

5.2. Influence of Different Desorption Methods on the Resistivity of Coal. Comparing the coal resistivities for gas desorption in Figures 4 and 6, it was found that the resistivity showed a linear relationship with gas content for both methods, but showed greater variation during isovolumetric desorption than for continuous desorption. However, the resistivity in the former case differed considerably from its original value when desorption was complete, which indicates greater residual deformation in the coal after isovolumetric desorption [25], as shown in Table 3.

The damage sustained by the coal sample due to gas absorption/desorption has less influence on the coal resistivity than the residual gas content; therefore, it can be ignored. At the same time, the linear relationship between resistivity and gas content of coal was used to fit the variation curves of the resistivity of coal containing gas at different equilibrium pressure conditions during the desorption process. The results are shown in Table 4.

From the fitting results in Table 4, the formula for the relationship between the resistivity of dry coal and gas content is expressed as

$$
q=\frac{\rho-b}{a}
$$

where $q$ is the gas content, $\rho$ is the coal resistivity, $a$ is a constant independent of the original gas content and related only to the slope of the resistivity gas desorption curve, and $b$ is a logarithmic function related to the initial gas content.

\section{Conclusions}

The influence of gas adsorption/desorption on the resistivity of coal was studied by measuring the change of resistance in a coal sample during continuous gas adsorption/desorption 
TABLE 3: Variation of coal resistivity following continuous desorption and isovolumetric desorption.

\begin{tabular}{lccc}
\hline $\begin{array}{l}\text { Experimental } \\
\text { method }\end{array}$ & $\begin{array}{c}\text { Equilibrium } \\
\text { pressure }(\mathrm{MPa})\end{array}$ & $\begin{array}{c}\text { Content of } \\
\text { residual gas } \\
(\mathrm{mL} / \mathrm{g})\end{array}$ & $\begin{array}{c}\text { Rate of } \\
\text { change }\end{array}$ \\
\hline $\begin{array}{l}\text { Continuous } \\
\text { desorption }\end{array}$ & 0.534 & 8.57 & $21.8 \%$ \\
$\begin{array}{l}\text { Isovolumetric } \\
\text { desorption }\end{array}$ & 0.72 & 6.23 & $41.9 \%$ \\
\hline
\end{tabular}

TABLE 4: Fitting results of relationship between resistivity of coal and gas content in the continuous desorption process.

\begin{tabular}{lcc}
\hline $\begin{array}{l}\text { Equilibrium } \\
\text { pressure(MPa) }\end{array}$ & Fitted curve & $\begin{array}{c}\text { Correlation } \\
\text { coefficient }\left(R^{2}\right)\end{array}$ \\
\hline 0.343 & $\rho=-0.093 q+1.328$ & 0.9985 \\
0.442 & $\rho=-0.077 q+1.461$ & 0.9904 \\
0.534 & $\rho=-0.095 q+1.976$ & 0.9979 \\
\hline
\end{tabular}

and during isovolumetric gas adsorption/desorption. The conclusions are as follows:

(1) The resistivity of coal containing gas increased linearly with the reduction of gas content in desorption. In practical industry applications, the gas content of coal can be predicted by measuring the coal resistivity.

(2) During gas adsorption, the coal resistivity decreased with increasing gas content. When adsorption reached equilibrium, the resistivity tended to be stable with increasing gas content.

(3) The test results under different conditions of adsorption equilibrium pressure were different. The larger the adsorption equilibrium pressure is, the larger the swelling deformation of coal is, the closer the contact of coal particles is, the smaller the pore volume is, and the more obviously the resistivity changes. Because of the residual deformation of the coal after the gas is desorbed, the coal sample is not restored to its original condition. The resistivity of the coal containing residual gas after desorption is less than before the gas was adsorbed.

(4) A comparison of the ranges of coal resistivity for the same gas content adsorbed by different methods showed that the range of values for the isovolumetric method was significantly greater than for the continuous method. That is because, in the isovolumetric gas adsorption, the gas pressure on the coal sample caused the gas to be more evenly distributed throughout the coal, producing clear changes of resistivity. Similarly, for the two desorption modes, the residual deformation of the coal was greater following isovolumetric gas desorption, such that the final resistivity differed from its preadsorption value far more than in continuous gas desorption.

\section{Data Availability}

The data used to support the findings of this study are included within the article.

\section{Conflicts of Interest}

The authors declare that there are no conflicts of interest regarding the publication of this paper.

\section{Acknowledgments}

This study was supported by the National Natural Science Foundation of China (Grant No. 21373146), and the authors thank International Science Editing (http://www. internationalscienceediting.com) for editing this manuscript.

\section{References}

[1] Y. P. Cheng, Theories and Engineering Applications on Coal Mine Gas Control, China University of Mining and Technology, Xuzhou, China, 2010.

[2] W. P. Diamond and S. J. Schatzel, "Measuring the gas content of coal: a review," International Journal of Coal Geology, vol. 35, no. 1-4, pp. 311-331, 1998.

[3] State Administration of Work Safety of China, Prevention and Control of Coal and Gas Outburst, State Administration of Work Safety of China, Beijing, China, 2009.

[4] S. P. Peng, W. F. Du, C. Y. Yan, and G. G. Ju, "Coal-bed gas content prediction based on avo inversion," Journal of China Coal Society, vol. 39, no. 9, pp. 1792-1796, 2014.

[5] X. L. Zhang, J. P. Shan, and S. P. Peng, "Mathematical geology technique and method for prediction of gas content and emission," Journal of China Coal Society, vol. 34, no. 3, pp. 350-354, 2009.

[6] W. C. Wang and R. Z. Wang, "Prediction of mine gas content based on generalized regression neural network GRNN," China Coalbed Methane, vol. 7, no. 1, pp. 37-41, 2010.

[7] H. Dindi, X. H. Bai, and W. B. Krantz, "Thermal and electrical property measurements for coal," Fuel, vol. 68, no. 2, pp. 185-192, 1989.

[8] S. M. Mahmood, N. L. Maerefat, and M. M. Chang, "Laboratory measurements of electrical resistivity at reservoir conditions," Spe Formation Evaluation, vol. 6, no. 3, pp. 134-143, 1991.

[9] S. Marland, A. Merchant, and N. Rowson, "Dielectric properties of coal," Fuel, vol. 80, no. 13, pp. 1839-1849, 2001.

[10] L. J. Xu, C. L. Liu, and X. F. Xian, "Effect of frequency on electric conductivity of coal in outburst zone," Mining Safety \& Environmental Protection, vol. 27, no. 6, pp. 25-26, 2000.

[11] H. W. Xu, "Measurement and test of seam electric parameter and study on relationship between seam electric parameter and coal petrology characteristics," Coal Science \& Technology, vol. 33, no. 3, pp. 42-47, 2005.

[12] Y. Wang, E. Wang, Z. Li, X. Liu, and Z. Liu, "Feasibility study on the prediction of coal bump with electrical resistivity method," in Progress in Mining Science and Safety Technology, pp. 465-472, Science Press, Beijing, China, 2007.

[13] S Yang, Experimental Study on the Electrical Parameters of the Load Bearing Gas Coal, Henan Polytechnic University, Jiaozuo, China, 2012. 
[14] Z. X. Liu and Z. C. Feng, "Theoretical study on adsorption heat of methane in coal," Journal of China Coal Society, vol. 37, no. 4, pp. 647-653, 2012.

[15] X. Su, R. Chen, X. Lin, and Y. Song, "Application of adsorption potential theory in the fractionation of coal bed gas during the process of adsorption/desorption," Acta Geologica Sinica, vol. 82, no. 10, pp. 1382-1389, 2008.

[16] D. Zhou, Z. C. Feng, D. Zhao, L. Wang, and X. L. Wang, "Study on mesoscopic characteristics of methane adsorption by coal," Journal of China Coal Society, vol. 40, no. 1, pp. 98-102, 2015.

[17] Y. Yao and S. Zhou, "The mechanical property of coal containing gas," Journal of China University of Mining \& Technology, vol. 17, no. 1, pp. 1-7, 1988.

[18] G. P. Zhou, X. F. Xian, Y. D. Jiang, D. S. Gu, and C. Wang, "A model of adsorption induced coal deformation based on thermodynamics approach," Journal of China Coal Society, vol. 36, no. 3, pp. 468-472(5), 2011.

[19] X. Q. He, Flowage Dynamics of Gas Bearing Coal and Gas, China University of Mining and Technology Press, Xuzhou, China, 1995.

[20] Q. T. Hu, Study on the Mechanism of Coal and Gas Outburst and its Application, China University of Mining and Technology, Xuzhou, China, 2007.

[21] B. Q. Lin and S. N. Zhou, "Experimental investigation on the deformation law of coal body containing methane," Journal of China University of Mining and Technology, vol. 3, pp. 9-16.

[22] Z. F. Lv, X. M. Zhang, L. W. Zhong et al., "The pore features of lump coal and its influence factors," Journal of China University of Mining and Technology, vol. 20, no. 3, pp. 45-51, 1991.

[23] B. S. Nie, L. Zhang, and W. F. Ma, "Diffusion micromechanism of coal bed methane in coal pores," Coal Geology \& Exploration, vol. 28, no. 6, pp. 20-22, 2000.

[24] E. Y. Wang, X. Q. He, and H. Y. Lin, "Occurrence of gas in coal," Coal Engineer, no. 5, pp. 12-19, 1996.

[25] B. Nie, S. Hu, X. Li, S. Zhai, and J. Meng, "Experimental study of deformation rules during the process of gas adsorption and desorption in briquette coal," International Journal of Surface Mining Reclamation \& Environment, vol. 28, no. 5, pp. 277286, 2014. 


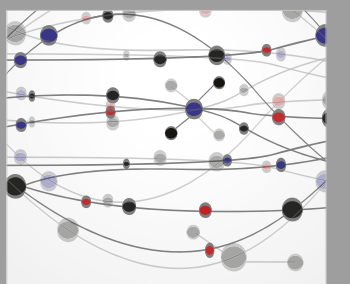

The Scientific World Journal
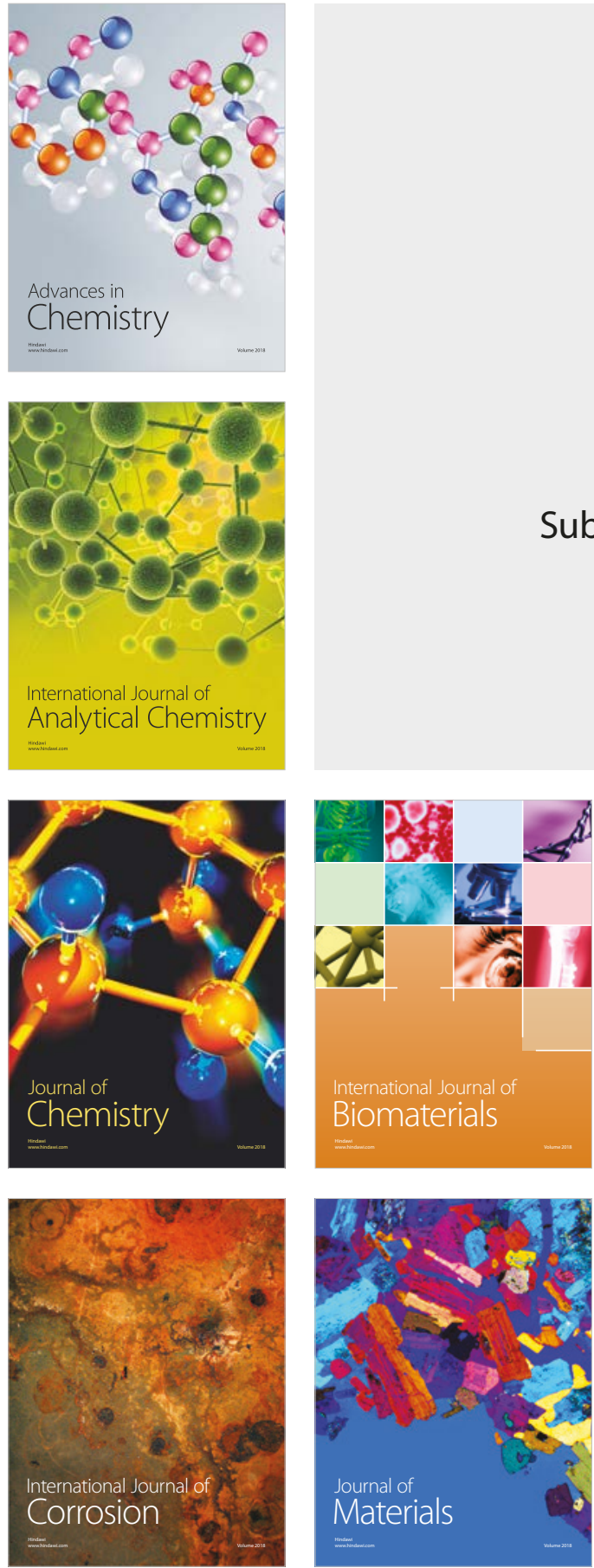

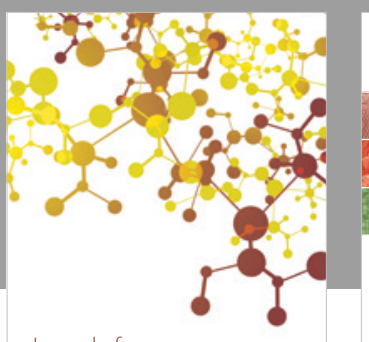

Journal of

Applied Chemistry
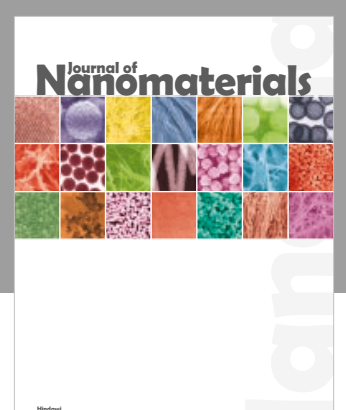

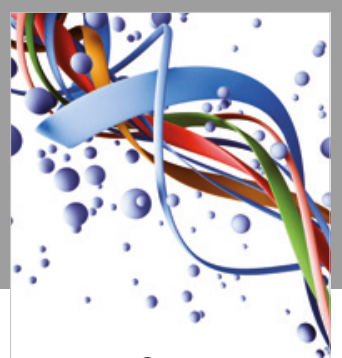

Scientifica

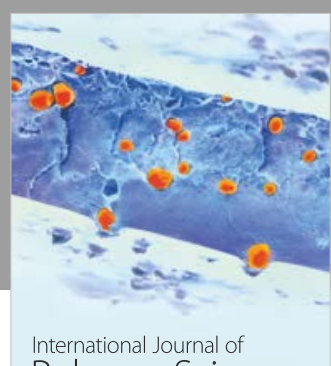

Polymer Science

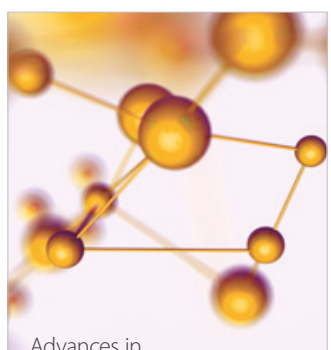

Physical Chemistry
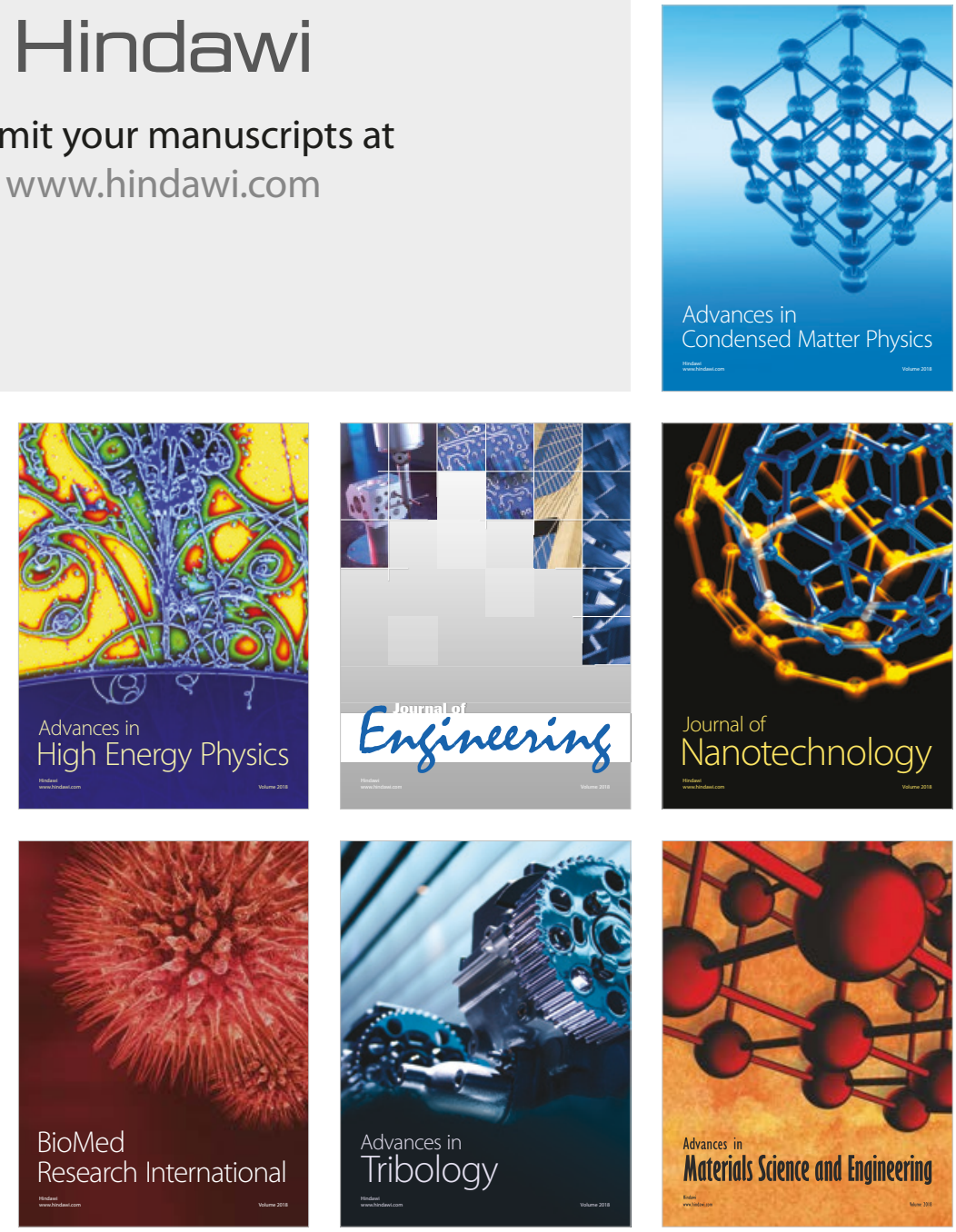